\title{
Variability of Extreme Temperature in the Arctic - Observation and RCM
}

\author{
Heidrun Matthes ${ }^{*}$, Annette Rinke and Klaus Dethloff
}

Alfred Wegener Institute for Polar and Marine Research, Potsdam, Germany

\begin{abstract}
This paper discusses results of a simulation with the regional climate model HIRHAM for 1958-2001, driven by the ECMWF reanalysis (ERA40) data over the Arctic domain. The aim is to analyze the ability of the model to capture certain features of climate extremes derived from daily mean, maximum and minimum temperatures. For this purpose, a range of climate indices (frost days, cold and warm spell days, growing degree days and growing season length) was calculated from the model output as well as from ERA40 data and region-specific station data for Eastern and Western Russian Arctic for comparison. It is demonstrated that the model captures the main features in the spatial distribution and temporal development of most indices well. Though systematic deviations in the seasonal means occur in various indices (frost days, growing degree days), variability and trends are well reproduced. Seasonal mean patterns in frost days are reproduced best, though the model persistently calculates too many frost days. Seasonal means of cold and warm spell days are reproduced without systematic biases, though deviations occur in summer for cold spells and in spring and summer for warm spells due to an early spring warming in the regional climate model and a low variability of the daily maximum temperature over sea ice.
\end{abstract}

Keywords: Arctic temperature, climate extremes, regional climate modelling.

\section{INTRODUCTION}

The change in climate extremes is an important aspect of global warming, as it effects the live of people in form of heat waves or changes in the growing season length very directly. The Arctic has now widely been accepted as an area especially sensitive to climate change, this change will result in changes of climate extremes as well. It is suggested that extremely warm temperatures may occur with a greater frequency (e.g., Rinke and Dethloff [1]). Recent analysis of extremes from observations using climate indices like frost days for the Arctic have shown high variability and warming trends for specific areas in the Arctic regions. Alexander et al. [2] calculated a decrease in frost days and cold spell days over most of the Arctic. Matthes et al. [3] additionally show an increase in growing degree days over the Arctic domain and an increase in the growing season length especially over Western Russia and Alaska.

To estimate possible future changes in climate extremes, it is necessary to apply climate models that are able to reproduce the "present-day" extremes. In this context, not only the magnitude and trend of extremes but also their variability is of importance. Very few studies have aimed at assessing the ability of climate models to reproduce climate extremes. For example, Kiktev et al. [4] used output from the global circulation model HadAM3 from 1950-1995 to calculate frost days. The model well reproduces the natural variability of the index, but the ability of the model to capture the observed trend patterns strongly depends on the sea surface temperature forcing used. However, a detailed

*Address correspondence to this author at the Alfred Wegener Institute for Polar and Marine Research, Telegrafenberg A43, D-14473 Potsdam, Germany; Tel: +49 331 2882101; Fax: +49 331 2882178;

E-mail: Heidrun.Matthes@awi.de comparison for high latitudes was prevented by the lack of data in the observational data set.

Here, we present data from the regional climate model HIRHAM, applied over the pan Arctic domain for present day. Climate extreme indices were calculated from the model output and compared to ERA40 reanalysis data. Additionally, we put a regional focus on the Russian Arctic due to the CARBO-North project ("Quantifying the carbon budget in Northern Russia: past, present and future"; http://www.carbonorth.net/) in which this study is residing, using an extensive station data set. We aim at demonstrating the ability of the model to reproduce spatial patterns as well as temporal development and variability of the chosen climate indices.

This paper continues in section 2 with a description of the model, used data sets and data analysis. Section 3 presents the comparison of modeled and observed spatial patterns and time series. The results are summarized in section 4 .

\section{DATA, MODEL AND ANALYSIS}

\subsection{Daily Temperature Datasets}

Two different data sets are used in the following analysis: the ERA40 reanalysis data (Uppala et al. [5]) for the spatial comparison of the model results and the station data set "Global Summary of the Day" (GSOD; www.ncdc.noaa. gov//oa/mpp/freedata.html) provided by the National Climatic Data Center for the in-depth regional comparison. Daily mean, minimum, and maximum temperature are analyzed from both data sets for the pan-Arctic (Matthes et al. [3]).

The ERA40 data north of $60^{\circ} \mathrm{N}$ and for the period 1958 2001 are used and interpolated to the HIRHAM model grid for the comparison. The station data set GSOD contains 644 
stations located in the Russian Arctic and north of $60^{\circ} \mathrm{N}$ (Fig. 1). These station data are analyzed for the period from 1958 to 2008. It is necessary to mention that almost no station has full data coverage over the whole 51-year-long period. To account for the spatially different climatology within the Russian Arctic, the station data is split into two parts, GSOD east (324 stations) and GSOD west (320 stations), using the Ural mountains as separation.

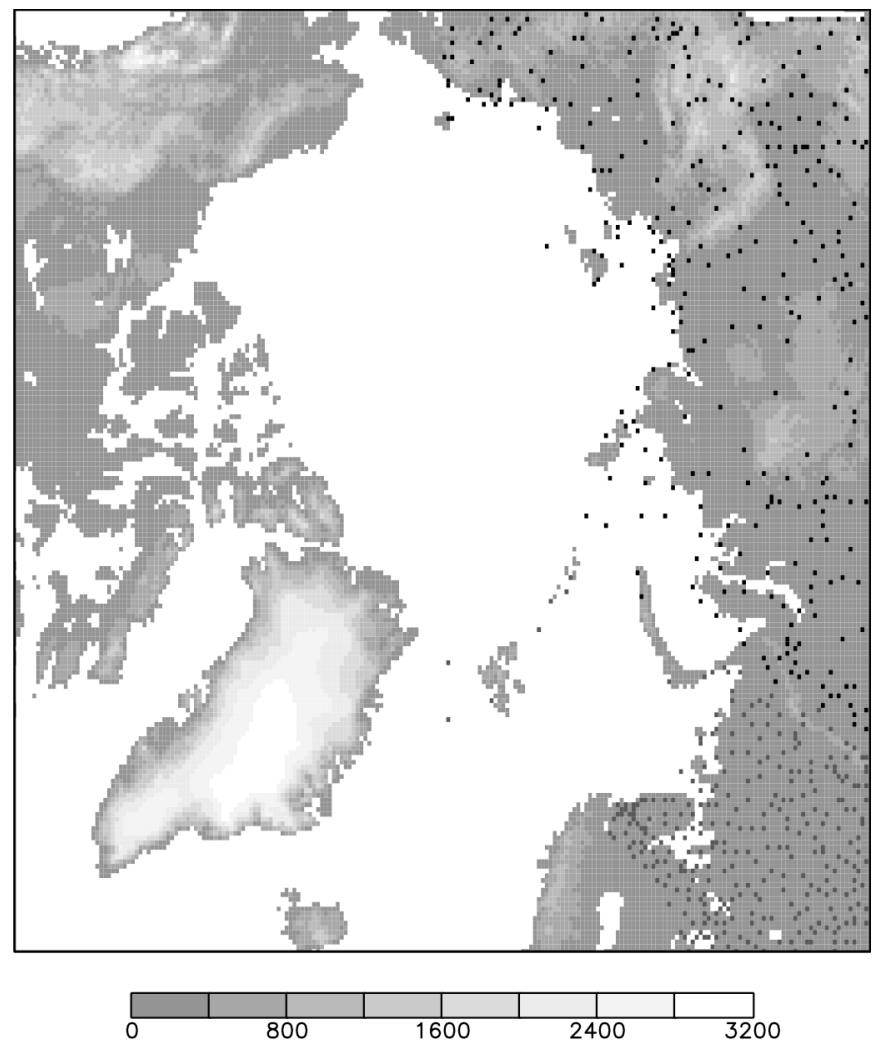

Fig. (1). Map of station distribution of the GSOD data set. In total, daily data from these 644 stations have been analyzed (324 stations in eastern part plotted black, 320 stations in western part plotted dark grey). Shades refer to the orographic height [m].

\subsection{Model Description}

The climate simulation over the Arctic domain is performed using the regional atmospheric climate model HIRHAM, developed by Christensen et al. [6] and adapted for simulations of the Arctic climate by Dethloff et al. [7]. In this model, the dynamical core is from HIRLAM (Gustafsson [8]), while the physical parameterization package comes from ECHAM4 (Roeckner et al. [9]). The standard ground scheme of the HIRHAM model was replaced by the more sophisticated Land Surface Model (LSM) (Bonan, Saha et al. [10-11]). HIRHAM includes prognostic equations for temperature, surface pressure, horizontal wind components, specific humidity and cloud water.

The integration domain applied for the Arctic covers the area north of ca. $60^{\circ} \mathrm{N}$ (Fig. 1). A horizontal resolution of $0.25^{\circ}$ (or ca. $25 \mathrm{~km}$ ) is used. The vertical resolution in the simulation is given by 19 unequally spaced levels, with intervals increasing with height from about $35 \mathrm{~m}$ near the surface to about $3900 \mathrm{~m}$ maximum. The simulation is driven by the ERA40 reanalysis data on the lateral and lower boundaries and comprehends the period 1958-2001. Sea ice is prescribed daily from the ERA40 data and treated with a constant thickness of $2 \mathrm{~m}$. For boundary forcing, a boundary relaxation zone of 20 grid points is used. No large-scale nudging is applied.

\subsection{Climate Indices and Trend Analysis}

Table 1 shows the classification of extreme temperatures, based on climate indices (Peterson et al. [12]). In addition to air temperature, the paper also presents indices illustrating vegetation conditions (growing season length, growing degree days) and frost conditions (frost days). These indices and their trends were calculated for the two observational data sets of GSOD and ERA40, and for the HIRHAM simulation.

Table 1. Classification of Extreme Temperature Based on Climate Indices

\begin{tabular}{|l|l|l|}
\hline frost days & FD & $\begin{array}{l}\text { \# of days per season with t_min }< \\
0^{\circ} \mathrm{C}\end{array}$ \\
\hline cold spell days & CSDI & $\begin{array}{l}\text { \# of at least } 6 \text { consecutive days } \\
\text { with t_min }<\text { TN10 }\end{array}$ \\
\hline cold nights & TN10p & $\begin{array}{l}\text { \# of days per season with t_min }< \\
\text { TN10 }\end{array}$ \\
\hline warm spell days & WSDI & $\begin{array}{l}\text { \# of at least } 6 \text { consecutive days } \\
\text { with t_max }>\text { TX90 }\end{array}$ \\
\hline warm day-times & TX90p & $\begin{array}{l}\text { \# of days per season with t_max }> \\
\text { TX90 }\end{array}$ \\
\hline growing degree days & GD4 & $\begin{array}{l}\text { sum of daily mean temperature per } \\
\text { season for days with t_mean }>4{ }^{\circ} \mathrm{C}\end{array}$ \\
\hline growing season length & GSL & $\begin{array}{l}\text { \# of days between the first } \\
\text { occurrence of at least } 6 \text { consecutive } \\
\text { days with t_mean }>5^{\circ} \mathrm{C} \text { and the } \\
\text { first occurrence after the 1st July of } \\
\text { at least } 6 \text { consecutive days with } \\
\text { t_mean }<5^{\circ} \mathrm{C}\end{array}$ \\
\hline
\end{tabular}

TX90 is the $90^{\text {th }}$ percentile calculated from a five-day gliding mean of the daily maximum temperature of the reference period 1961-1990 and TN10 is the $10^{\text {th }}$ percentile calculated from a five-day gliding mean of the daily minimum temperature of the reference period. t_mean is used as denotation for the daily mean temperature, t_min and t_max for daily minimum and maximum temperature respectively.

To calculate the indices listed in Table $\mathbf{1}$, it is necessary to select the available data considering missing values. It is chosen to include station data into the analysis in case of 10 or less missing daily values of the input data value coming from the station for the specific season, except for indices counting consecutive days (e.g. cold spells). Indices falling under that rule include only seasons with full data coverage. The presented time series show a station mean for a specific season, if at least $10 \%$ of the stations deliver data for that season. In addition, absolute counters (frost days) are normalized on the maximum number of days in the season, considering the existence of missing values. Winters in leap years are scaled to a 90-day maximum. The presented time series also include the standard deviation development relative to a 11-year gliding mean (and assigned to the center of the 11-year window), in order to show the development of the inter-annual variability within the calculated time series.

Furthermore, trends in the climate indices are calculated using a linear regression with the least squares method. A bootstrapping approach as described in Kiktev et al. [4] is 
used to assess the significance of those trends. The trends in the gridded ERA40 data are analyzed in a similar way, the same re-sampling sequence was used for each grid point to account for possible spatial correlation (see again Kiktev et al. [4]). All trends marked statistically significant are significant at the $95 \%$-level. Significance is assigned to a zero trend, if the sum of squares of deviations from the mean was less than $5 \%$ of the mean. As the time series in the station data contain missing values, it is necessary to make sure that a shown trend is evenly based on values from the entire period. Therefore, the whole 51-year period is divided into four 11-year-long intervals and a 7-year-long interval for the rest (1958-1968, 1969-1979, 1980-1990, 1991-2001, 2002-2008). And thus, a trend for a certain period is only shown, if at least five years (respectively three years in the last period) of data are contained for each of these intervals within the trend's period.

To compare the HIRHAM data to the station data set, the modeled data is linearly interpolated from the surrounding grid points onto the station locations. Missing values in the station records are blanked in the modeled data as well. About one third of the stations cover 40 or more of the 44 years, all other stations contribute at least one season in a specific year. To quantify the comparison of the spatial distribution of the climate indices and their trends calculated by HIRHAM and ERA40, statistical parameters like bias ("HIRHAM minus ERA40"), root mean square error (rmse) and pattern correlation coefficient (pcc) are computed. The latter describes whether the spatial distribution of a simulated index fits with the observed pattern even if the bias is distinguished. In its evaluation the following thresholds are applied: $p c c>0.9$ high agreement, $p c c=0.7-0.9$ good, $\mathrm{pcc}=0.5-0.7$ reasonable, $\mathrm{pcc}<0.5$ poor.

\section{RESULTS}

\subsection{Frost Days}

Fig. (2) shows the seasonal mean patterns of frost days in the transition seasons, averaged over the 44-year period of 1958-2001, as modeled by HIRHAM. Maximum numbers of frost days occur over the Arctic Ocean and Greenland in both seasons. In autumn, the number of frost days is still reduced from summer and therefore the area of maximum numbers is smaller than in spring. In comparison with ERA40, the pattern correlation coefficients are equally high $(\mathrm{pcc}=0.93$, see Table 2) for both seasons, showing that the spatial distribution of frost days is well reproduced by the model. A detailed comparison of the simulated patterns with those of ERA40 data (see isolines in Fig. (2), and see Fig. (2) in Matthes et al. [3]) shows that the model is too cold in both seasons over most of the Arctic (resulting in too many frost days), except over the Atlantic Ocean, Norwegian and Kara Seas and inner Greenland. The positive bias (6-12 days) occurring over Eastern Siberia can partly be explained by a known lack of cyclone activity in that area (Rinke et al. [13]), which is stronger in autumn than in spring. The positive biases over high mountain ranges like the Ural mountains, Alaskan and East Siberian mountains are due to the higher horizontal resolution of HIRHAM, which leads to a more appropriate representation of the orography. The resulting increased height of the mountain ranges is in line with lower temperatures, therefore frost days are increased.
In spring, a negative bias (up to 8days) is found in coastal areas, especially at Taimyr Peninsula and Canada.
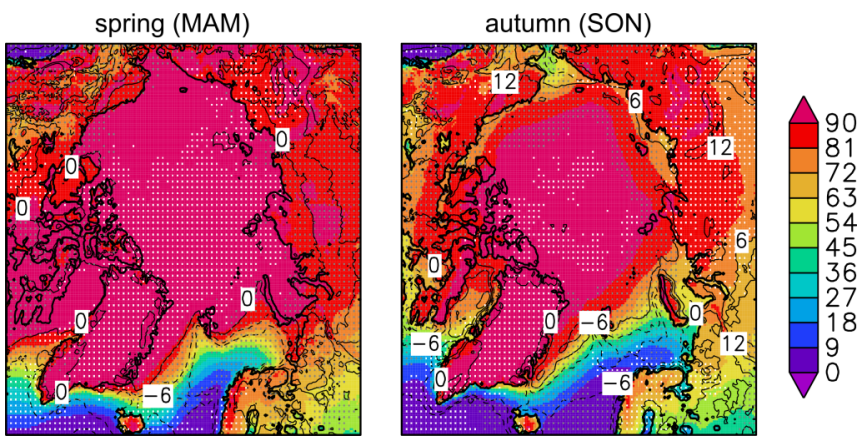

Fig. (2). Seasonal patterns of frost days in spring (left panel) and autumn (right panel), based on the HIRHAM simulation, 19582001. The colors show the seasonal mean [days]. The dotted regions represent those areas which have the same trend sign in both ERA40 and HIRHAM. The white (grey) dotted areas indicate positive or zero (negative) trends. Bias, rmse and pcc for frost days and their trends are given in Table 2. The black isolines signify the difference ERA40 minus HIRHAM, the isoline spacing is 6 days.

Table 2. Bias [Days resp. Days/Decade], Root Mean Square Error (rmse) [Days resp. Days/Decade] and Pattern Correlation Coefficient (pce) of Frost Days (left) and Trend Over 1958-2001 in Frost Days (right), Comparison Between HIRHAM and ERA40. For Details see Section 2.3

\begin{tabular}{|c|c|c|}
\hline & Frost Days & Trend in Frost Days \\
\hline \multicolumn{3}{|l|}{ Spring } \\
\hline bias & -1.12 & -0.05 \\
\hline rmse & 7.56 & 0.8 \\
\hline pcc & 0.93 & 0.58 \\
\hline \multicolumn{3}{|l|}{ Autumn } \\
\hline bias & -3.67 & 0.24 \\
\hline rmse & 9.67 & 0.7 \\
\hline pcc & 0.93 & 0.64 \\
\hline
\end{tabular}

Additionally, Fig. (2) shows a comparison of the calculated trends in frost days for ERA40 and the modeled results. The trends are in the order of \pm 0.8 days/decade with most trends being within \pm 0.2 days per decade (see Matthes et al. [3]). The calculated HIRHAM trends have the same sign as the ERA40 trends over most of the domain (see dotted areas in Fig. 2). The few areas with a different sign are characterized by very small, not statistically significant trends. The pattern correlation of the trends between ERA40 and HIRHAM is not as high as for frost days themselves (see Table 2) but the reasonable pattern correlation ( $\mathrm{pcc}=0.6$ ) shows that the modeled trends are in an adequate agreement with that of the reanalysis.

In Fig. (3), the regional analysis of frost days is presented for Eastern and Western Russian Arctic based on the HIRHAM simulation and station data. In agreement with what was found in the comparison of the simulation with ERA40 data, the model is too cold (i.e. has higher numbers 
of frost days) compared to the observed data. Thus, a systematic offset of ca. 3-4 (5-10) days between both time series for Western (Eastern) Russia is obvious. However, the remarkable year-to-year variability of the frost days observed in the station data is well reproduced by the model. In both data sets a significantly lower variability in spring than in autumn and in Eastern than in Western Russian Arctic is found. That effect is due to a higher variability in frost days when temperatures are closer to the $0^{\circ} \mathrm{C}$ threshold that is used to calculate them, as then the variability in air temperature translates into that of frost days. The bars in Fig. (3) characterize the inter-annual variability over the analyzed time period (see section 2.3), and clearly show that the model reproduces both the magnitude of this variability and its decadal-scale pattern. The figure further shows that the model captures the tendencies in frost days. The calculated trends are depicted as lines in Fig. (3), the exact values and significances can be found in Table 3. The trends for Western Russian Arctic are positive for the long periods (1958-2008, 1958-2001) and negative for the short periods (1969-2001, 1980-2001), for both the model and the station data. The decrease in frost days from the early 1990s on causing the change in the trend sign is well reproduced by the model, although the trend magnitudes are different. Over the Eastern Russian Arctic, the trends in spring are negative for all periods, for both the model and the station data, and the trends are similar in their order of magnitude. The shortterm trends (1980-2001) are found statistically significant with a decrease of frost days of ca. 1.8 days/decade. In autumn, all calculated GSOD east trends are positive (except for 1958-2008 based on station data). The trends in autumn in the model and station data have the same sign and similar order of magnitude, and none are found statistically significant.

\subsection{Cold Spell Days}

Cold spell days are a measure of lasting cold periods. The spatial distributions of their seasonal means as calculated from HIRHAM are shown in Fig. (4). Cold spells occur in
Table 3. Seasonal Trends of Frost Days [Days/Decade] in Spring and Autumn, Covering Different Time Periods

\begin{tabular}{|l|l|l|l|l|}
\hline \multirow{2}{*}{} & \multicolumn{2}{|c|}{ GSOD West } & \multicolumn{2}{c|}{ GSOD East } \\
\cline { 2 - 5 } & GSOD & HIRHAM & GSOD & HIRHAM \\
\hline \hline
\end{tabular}

\begin{tabular}{|c|c|c|c|c|}
\hline \hline \multicolumn{5}{|l|}{ Spring } \\
\hline 51 yrs (1958-2008) & 0.52 & & $-0.69^{*}$ & \\
\hline 44 yrs (1958-2001) & 1.31 & 0.23 & -0.49 & -0.62 \\
\hline 33 yrs (1969-2001) & -0.40 & -1.54 & -0.73 & $-1.05^{*}$ \\
\hline 22 yrs (1980-2001) & -3.31 & -3.09 & $-1.73^{*}$ & $-1.89^{*}$ \\
\hline
\end{tabular}

\begin{tabular}{|c|c|c|c|c|}
\hline \multicolumn{5}{|l|}{ Autumn } \\
\hline 51 yrs (1958-2008) & 0.62 & & -0.13 & \\
\hline 44 yrs (1958-2001) & 1.55 & 0.18 & 0.50 & 0.37 \\
\hline 33 yrs (1969-2001) & -0.43 & -0.97 & 0.43 & 0.20 \\
\hline 22 yrs (1980-2001) & -0.54 & -0.95 & 0.66 & 0.96 \\
\hline
\end{tabular}

The numbers are given for station-based (GSOD) and HIRHAM data (for details see the text of section 2). Statistically significant trends are marked with an asterisk.

all seasons, with a clear minimum in summer. Distinct areas of maximum cold spell occurrence are the Baffin Bay (up to 8 days in winter and spring, 6 days in autumn), the region around Novaya Zemlya (up to 8 days in winter and transition seasons) and Eastern Siberia (also up to 8 days in spring and autumn). These simulated patterns agree with those of the ERA40 data (Matthes et al. [3]). Based on ERA40 data, Matthes et al. [3] discussed that the occurrence of cold spells is associated with specific atmospheric circulation patterns. Years characterized by a high number of cold spell days over the Baffin Bay show a more prominent high over the Arctic Ocean and a more pronounced Icelandic low than on average, leading to cold north winds over Baffin Island and the Baffin Bay which then leads to an increase in cold spell days. Years with many cold spell days over central Siberia in
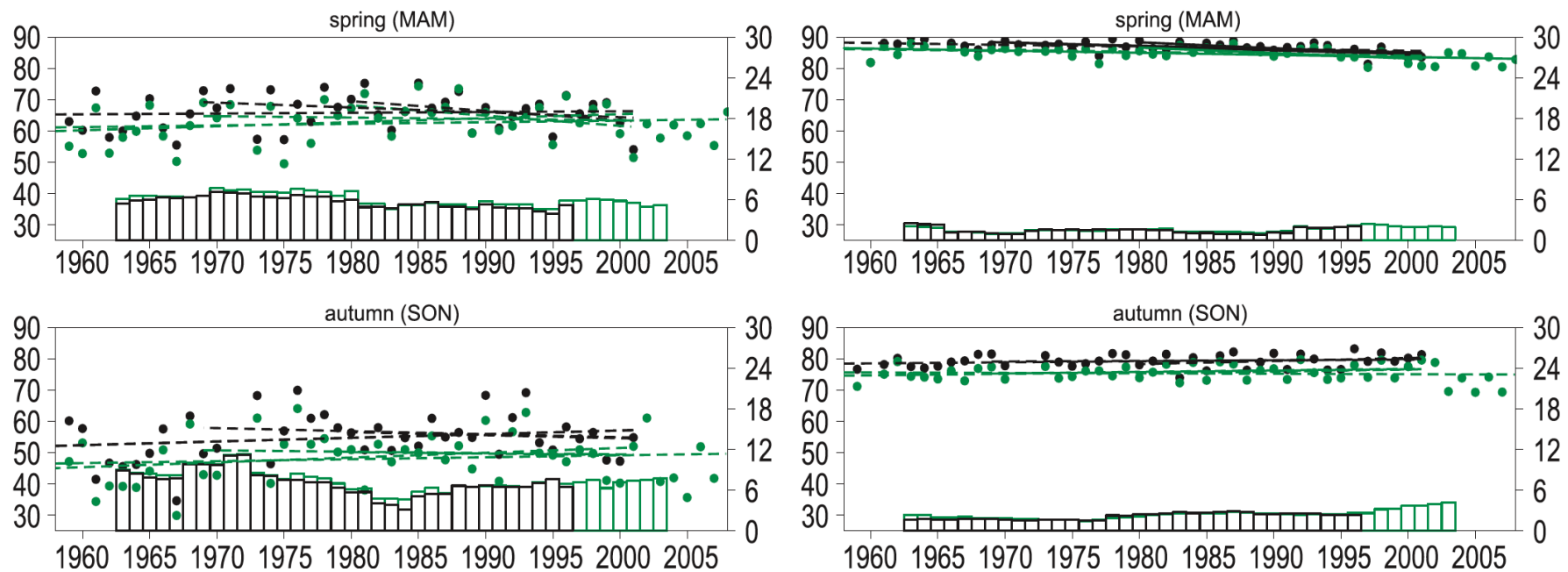

Fig. (3). Year-to-year variability and trends of frost days in spring (upper panels) and autumn (lower panels), 1958-2008, based on station data (green dots and lines) and HIRHAM (black dots and lines). The left y-axis is for the frost days [days] (dots), and the right y-axis is for the inter-annual variability [days] (bars). See text (section 2.3) for details. Left panel: GSOD west, right panel: GSOD east. The corresponding slopes of the trends and their significances are given in Table 3; statistically significant trends are plotted as solid lines. 

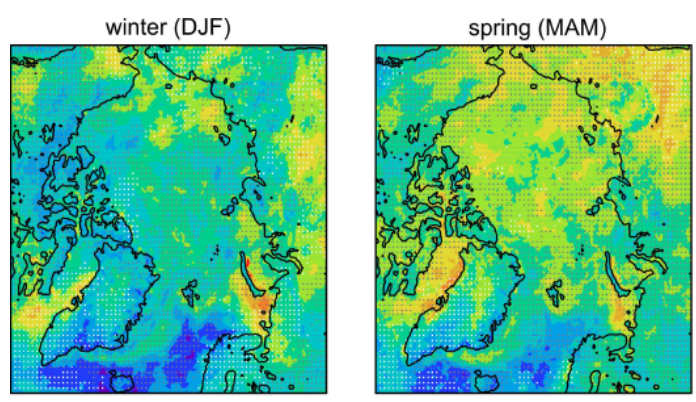

summer (JJA)
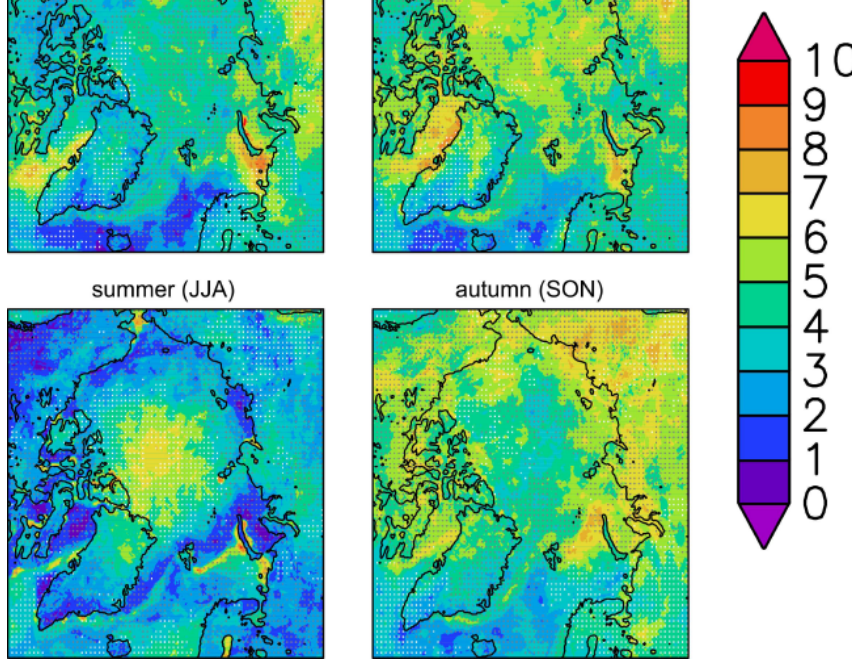

Fig. (4). Seasonal patterns of cold spell days, based on the HIRHAM simulation, 1958-2001. The colors show the seasonal mean [days]. The dotted regions represent those areas which have the same trend sign in both ERA40 and HIRHAM. The white (grey) dotted areas indicate positive ore zero (negative) trends. Bias, rmse and pcc for cold spell days and their trends are given in Table 4.

spring show a strong Arctic high which is largely extended towards the pole and the Russian coast, leading to stable, cold conditions over that area. The same inter-relationships can be confirmed for the HIRHAM simulations (not shown). The comparison with the ERA40 patterns (see Fig. 4 in Matthes et al. [3]) shows that except for summer, HIRHAM is able to reproduce the geographical patterns in cold spell days quite well. The pattern correlation coefficients are reasonable, between 0.57 and 0.65 (see Table 4). Also the absolute numbers of cold spells are of similar magnitude ( $\mathrm{rmse}=1$ day). However, in summer the agreement between HIRHAM and ERA40 is poor ( $\mathrm{rmse}=1.5$ day, $\mathrm{pcc}=0.3$ ). A closer inspection shows that this is mainly due to extended areas with a positive bias over Eastern Siberia and the central Arctic Ocean (i.e. HIRHAM simulates more cold spells there than ERA40). A similar error can also be found in cold nights, but not in the mean of the minimum temperature itself.

Additionally, an analysis of the calculated trends in cold spell days is shown in Fig. (4). Over almost all grid points, HIRHAM and ERA40 have the same sign (see dotted areas). Thus, the pattern correlation of the trends is reasonably high $(\mathrm{pcc}=0.64-0.68)$ and even larger than for the cold spell days themselves (Table 4). In summer, a difference in the trend sign is found over large parts of the central Arctic Ocean and the Central Siberian Uplands, and thus the pattern correlation is distinctly lower ( $\mathrm{pcc}=0.44)$.

In Fig. (5), the regional analysis of cold spell days for the Russian Arctic is presented. The temporal development of the index is well captured by the model, there is no systematic bias. All calculated trends from the modeled data are in the same order of magnitude as the trends from observed station data (see lines in the figure and Table 5). Also the inter-annual variability in the model shows the same magnitudes and decadal-scale variability as in the observation (see bars in the figure). For the Western Russian Arctic, all calculated trends are negative (except for autumn; see Table 5). This is due to a decrease in observed extreme

Table 4. Bias [Days resp. Days/Decade], Root Mean Square Error (rmse) [Days resp. Days/Decade] and Pattern Correlation Coefficient (pcc) of Cold and Warm Spell Days, and of their Trends Over 1958-2001, Comparison Between HIRHAM and ERA40. For Details see Section 2.3

\begin{tabular}{|c|c|c|c|c|}
\hline & Cold Spell Days & Trend in Cold Spell Days & Warm Spell Days & Trend in Warm Spell Days \\
\hline \multicolumn{5}{|l|}{ Winter } \\
\hline bias & 0.32 & 0.13 & -0.20 & 0.13 \\
\hline rmse & 1.09 & 0.8 & 1.03 & 0.7 \\
\hline pcc & 0.58 & 0.64 & 0.56 & 0.60 \\
\hline \multicolumn{5}{|l|}{ Spring } \\
\hline bias & 0.27 & -0.06 & 0.61 & 0.02 \\
\hline rmse & 1.01 & 0.6 & 2.15 & 1.0 \\
\hline $\mathrm{pcc}$ & 0.65 & 0.68 & -0.07 & 0.45 \\
\hline \multicolumn{5}{|l|}{ Summer } \\
\hline bias & 0.46 & 0.39 & -1.05 & 0.05 \\
\hline rmse & 1.50 & 0.9 & 2.27 & 1.7 \\
\hline $\mathrm{pcc}$ & 0.30 & 0.44 & 0.26 & 0.40 \\
\hline \multicolumn{5}{|l|}{ Autumn } \\
\hline bias & 0.22 & 0.16 & 0.20 & -0.31 \\
\hline rmse & 1.01 & 0.6 & 1.19 & 1.0 \\
\hline pec & 0.57 & 0.68 & 0.50 & 0.64 \\
\hline
\end{tabular}



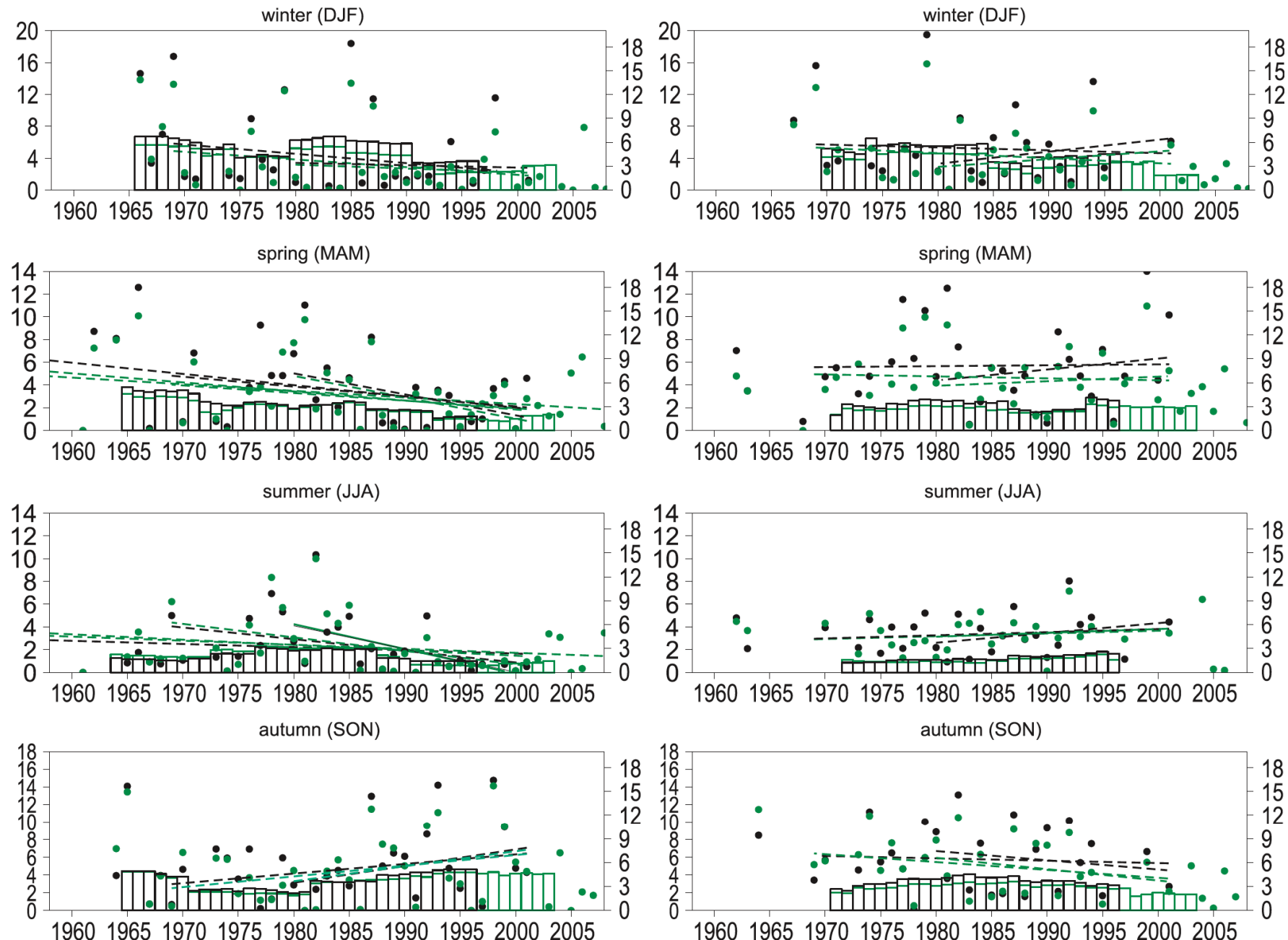

Fig. (5). Year-to-year variability and trends of cold spell days, 1958-2008, based on station data (green dots and lines) and HIRHAM (black dots and lines). The left y-axis is for the cold spell days [days] (dots), and the right y-axis is for the inter-annual variability [days] (bars). See text (section 2.3) for details. Left panel: GSOD west, right panel: GSOD east. The corresponding slopes of the trends and their significances are given in Table 5; statistically significant trends are plotted as solid lines.

high cold spell days which occurred regularly before the 1990 s and do not or only seldom occur thereafter. On the contrary in autumn, an increase in extreme high cold spell days occurred after the mid 1980s. Both the model and the observation show this behaviour. The only statistically significant trend in cold spells in the Western Russian Arctic is the strong short-term (1980-2001) trend of -2 days/decade in summer. For the Eastern Russian Arctic, only the shortterm trends could be calculated due to the many missing values in the station data (Table 5). These trends are small ( -0.2 to -1.5 days/decade), and none of them are found statistically significant. The sign varies among the periods and seasons referred to, but the simulated numbers and signs are in agreement with those of the station data.

\subsection{Warm Spell Days}

Fig. (6) shows the seasonal mean patterns of warm spell days for all seasons, based on the HIRHAM simulation. As cold spell days, warm spell days occur in all seasons. Maximum numbers of warm spell days (up to 10 days) are located over the Greenland Sea and Fram Strait, the Barents and Kara Seas in all seasons. In autumn, additionally maximum warm spell days are located at the Alaskan and
Russian shelves of the Arctic Ocean. The comparison of these simulated patterns with those from the ERA40 data (see Fig. 6 in Matthes et al., 2009) highlights both agreements and distinctions.

For both winter and autumn, the HIRHAM spatial warm spell patterns are similar to those of ERA40 data (pcc $=0.5$ 0.56 ; see Table 4).

In spring, no pattern correlation between HIRHAM and ERA40 is found ( $\mathrm{pcc}=-0.07)$. While the bias over Arctic land areas is within \pm 2 days, it is up to - 6 days over the Arctic Ocean. This bias is found in warm day-times equally, but much less strong. It is due to the fact that in HIRHAM, the spring warming of the air happens too early, a behaviour that was similarly found by Inoue et al. [14]. To demonstrate this shortcoming of the model exemplarily, Fig. (7) presents the daily $2 \mathrm{~m}$ maximum air temperature as calculated from both HIRHAM and ERA40, ranging from March 1 to August 31 1996 for two grid points of the HIRHAM model (marked in the summer panel of Fig. 6). One point is situated in the Canadian Basin $\left(72.0^{\circ} \mathrm{N}, 150.4^{\circ} \mathrm{W}\right)$, the other is in the central Arctic $\left(85.1^{\circ} \mathrm{N}, 172.7^{\circ} \mathrm{E}\right)$. For both points, a melting 
Table 5. Seasonal Trends of Cold Spell Days [Days/Decade] Covering Different Time Periods

\begin{tabular}{|c|c|c|c|c|}
\hline & \multicolumn{2}{|c|}{ GSOD West } & \multicolumn{2}{|c|}{ GSOD East } \\
\hline & GSOD & HIRHAM & GSOD & HIRHAM \\
\hline \multicolumn{5}{|l|}{ Winter } \\
\hline \multicolumn{5}{|l|}{51 yrs $(1958-2008)$} \\
\hline \multicolumn{5}{|l|}{44 yrs $(1958-2001)$} \\
\hline 33 yrs (1969-2001) & -0.97 & -1.17 & -0.64 & -0.36 \\
\hline 22 yrs $(1980-2001)$ & -0.48 & -0.29 & 0.98 & 1.52 \\
\hline \multicolumn{5}{|l|}{ Spring } \\
\hline 51 yrs $(1958-2008)$ & -0.58 & & & \\
\hline 44 yrs $(1958-2001)$ & -0.80 & -0.99 & & \\
\hline 33 yrs (1969-2001) & -0.67 & -0.87 & -0.17 & -0.08 \\
\hline 22 yrs (1980-2001) & -1.88 & -1.84 & 0.40 & 0.96 \\
\hline \multicolumn{5}{|l|}{ Summer } \\
\hline 51 yrs $(1958-2008)$ & -0.35 & & & \\
\hline 44 yrs $(1958-2001)$ & -0.47 & -0.27 & & \\
\hline 33 yrs (1969-2001) & -1.19 & -1.03 & 0.24 & 0.27 \\
\hline 22 yrs (1980-2001) & $-2.18 *$ & $-2.03 *$ & 0.34 & 0.86 \\
\hline \multicolumn{5}{|l|}{ Autumn } \\
\hline \multicolumn{5}{|l|}{51 yrs $(1958-2008)$} \\
\hline \multicolumn{5}{|l|}{44 yrs (1958-2001) } \\
\hline 33 yrs (1969-2001) & 1.20 & 1.11 & -0.88 & -0.26 \\
\hline 22 yrs $(1980-2001)$ & 1.69 & 1.87 & -1.28 & -1.04 \\
\hline
\end{tabular}

The slopes are given for station-based (GSOD) and HIRHAM data (for details see the text of section 2). Statistically significant trends are marked with an asterisk.

season can be defined, where the daily maximum temperature is bound to ca. $-2^{\circ} \mathrm{C}$ in HIRHAM and $1^{\circ} \mathrm{C}$ in
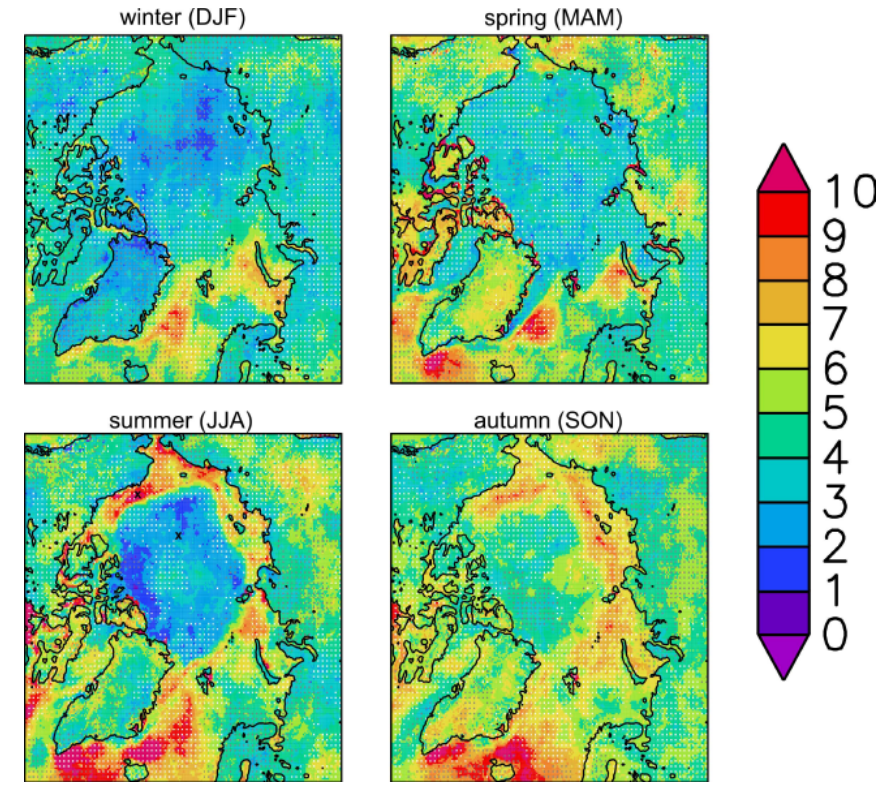

Fig. (6). Seasonal patterns of warm spell days, based on the HIRHAM simulation, 1958-2001. The colors show the seasonal mean [days]. The dotted regions represent those areas which have the same trend sign in both ERA40 and HIRHAM. The white (grey) dotted areas indicate positive ore zero (negative) trends. Bias, rmse and pcc for warm spell days and their trends are given in Table 4.

ERA40 (i.e. the incoming energy is used for melting the ice). Thereby, the absolute difference in these values between ERA40 and HIRHAM is due to the fact that ERA40 uses $0^{\circ} \mathrm{C}$ as ice melting point temperature, while HIRHAM uses $-1.7^{\circ} \mathrm{C}$. HIRHAM reaches the melting point about one month earlier than ERA40 for both points. This error is found in all years included in the analysis. The early HIRHAM warming leads to constantly high temperatures during late spring, which again leads to a high threshold TX90 (see Table 1). This threshold is seldom exceeded so that the calculated number of warm spell days is low. In ERA40, the spring is colder than in HIRHAM, and the threshold TX90 is lower.
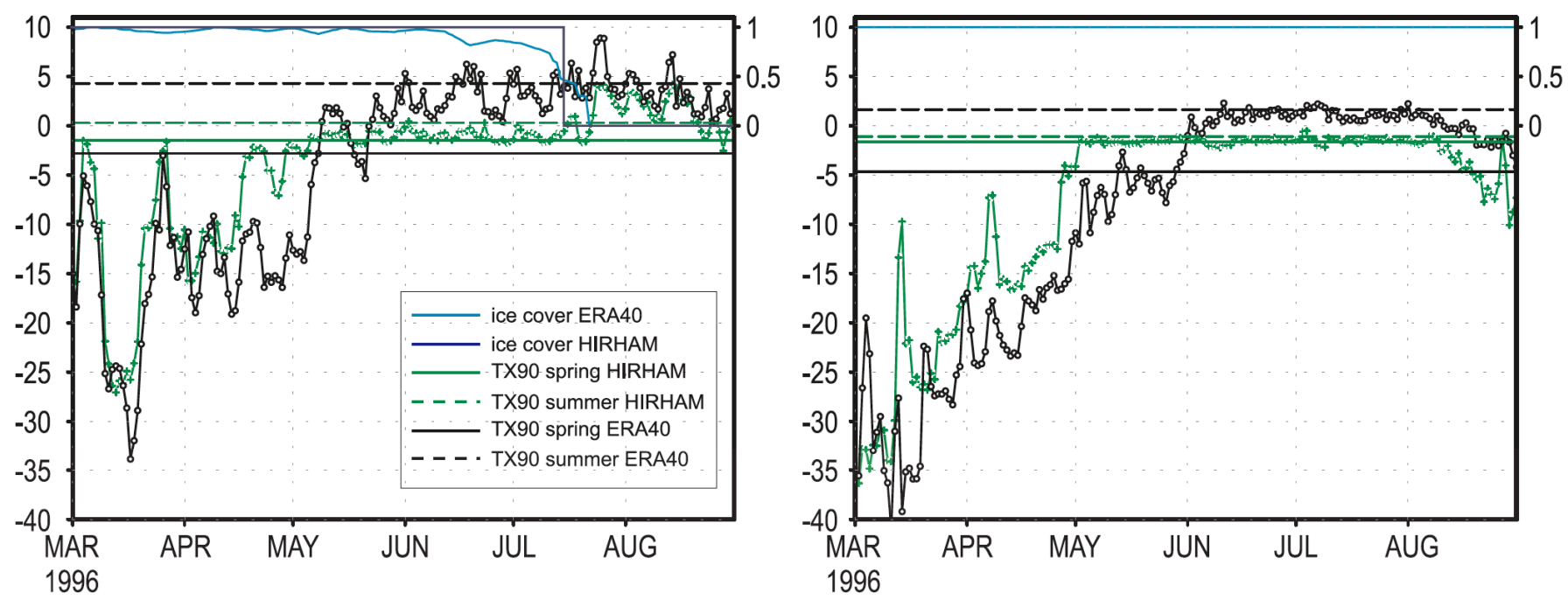

Fig. (7). Daily maximum temperature of ERA40 (black line) and HIRHAM (green line) and ice cover of ERA40 (blue line) and HIRHAM (violet line) for a grid point in the Canadian Basin $\left(72.0^{\circ} \mathrm{N}, 150.4^{\circ} \mathrm{W}\right)$ (left panel) and in the central Arctic $\left(85.1^{\circ} \mathrm{N}, 172.7^{\circ} \mathrm{E}\right)($ right panel). Left y-axis is for temperature $\left[{ }^{\circ} \mathrm{C}\right]$, right $\mathrm{y}$-axis is for ice cover. 
There is a steep increase in daily maximum temperature towards the end of spring, where TX90 threshold is exceeded frequently, causing a high number of warm spell days, unlike in HIRHAM.

In summer, the pattern correlation of warm spells between ERA40 and HIRHAM is also low ( $\mathrm{pcc}=0.26$; Table 4). A detailed comparison of both calculated patterns shows good agreement over land and the Norwegian and Greenland Seas. The low correlation again results from errors over the Arctic Ocean, especially over areas which regularly or at times become free of ice. This error is depicted in a simulated ring of high warm spell days along the coasts of Canada, Alaska and Russia (see the summer panel of Fig. 6) which does not appear in the ERA40 pattern (see Fig. 6 in Matthes et al. [3]). To understand this problem, the time series of the daily maximum $2 \mathrm{~m}$ air temperature for summer presented in Fig. (7) are discussed again. For the point in the central Arctic, which is ice-covered all summer, the daily maximum temperature is bound during the period of the ice melt to ca. $-2^{\circ} \mathrm{C}$ in HIRHAM and $1{ }^{\circ} \mathrm{C}$ in ERA40 (i.e. the incoming energy is used for melting the ice). For both models, the TX90 thresholds are close to the mean maximum temperatures due to the very low day-to-day variability and are therefore seldom exceeded. And thus, both models calculate similar numbers in warm spell days over icecovered areas. The grid point in the Canadian Basin, which eventually gets ice-free in mid-July, also shows a restriction of the daily maximum temperature during the period of the ice melt in the HIRHAM simulation (the temperatures are about $-1^{\circ} \mathrm{C} \pm 1{ }^{\circ} \mathrm{C}$ ). In contrast, the inter-daily air temperature variability in the ERA40 data during the same period is clearly higher, ranging within about $2^{\circ} \mathrm{C} \pm 2^{\circ} \mathrm{C}$. In late summer after the ice is melted (and the maximum temperature is free of restrictions), both HIHRAM and ERA40 show very similar day-to-day variability. Thus Fig. (7) demonstrates that the high variability in the ERA40 $2 \mathrm{~m}$ air temperature leads to a high TX90 threshold, which is seldom exceeded, while the low variability in HIRHAM during the early summer leads to a relatively low TX90 threshold, which is than permanently exceeded during the ice-free later summer period. This explains that HIRHAM calculates a much higher number of warm spell days than ERA40 in areas along the coast that eventually become ice free during summer. The differences described above between HIRHAM and ERA40 are due to 1) the fact that in ERA40, the lowest model level is at $10 \mathrm{~m}$ and thus about 20 $\mathrm{m}$ closer to the ground as in HIRHAM, and therefore its influence on the $2 \mathrm{~m}$ air temperature is more pronounced and 2) the different handling of ice cover (ERA40 allows for a fractional cover, while in HIRHAM as applied for the run presented here, no fractional ice cover is considered).
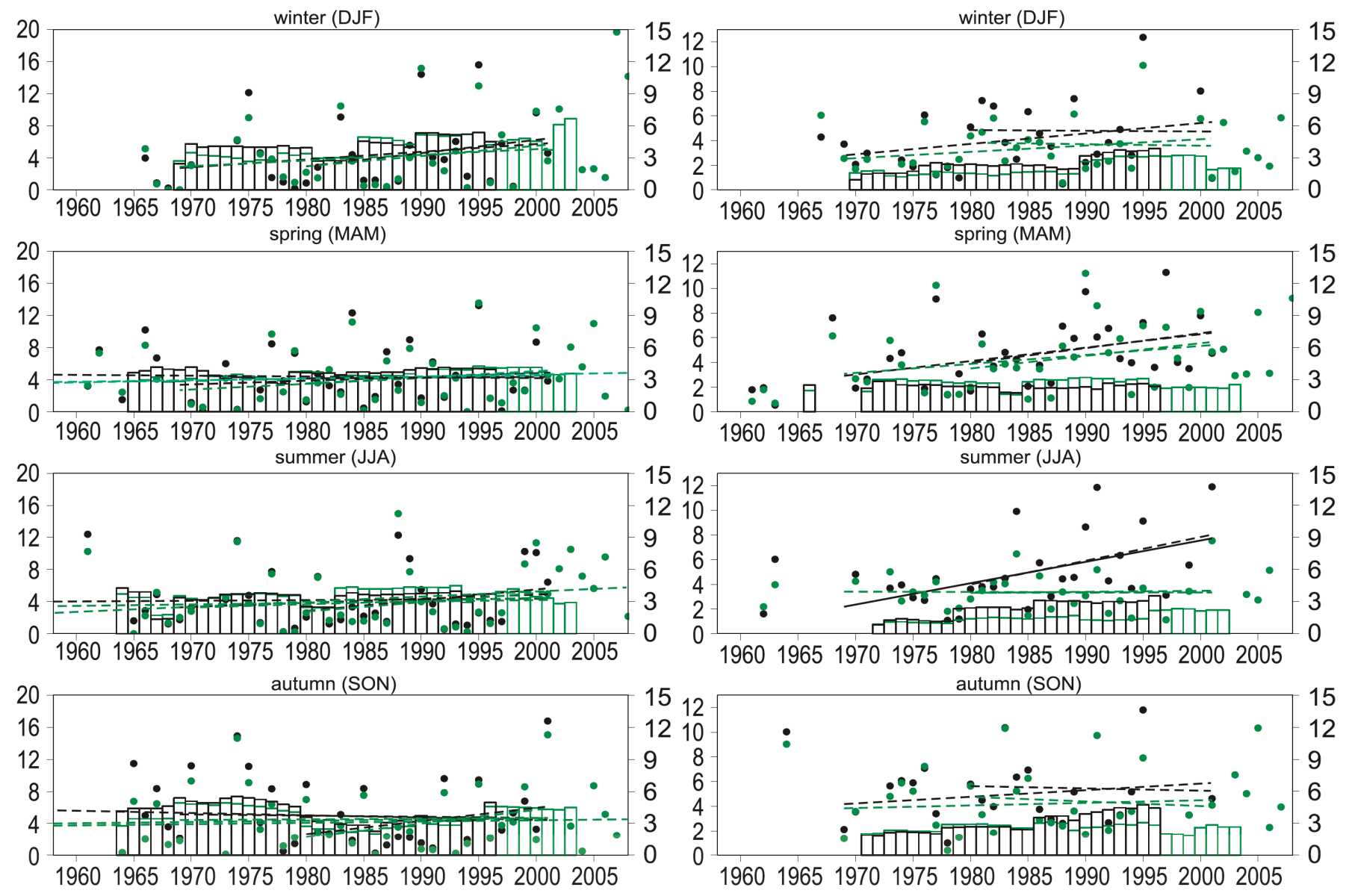

Fig. (8). Year-to-year variability and trends of warm spell days, 1958-2008, based on station data (green dots and lines) and HIRHAM (black dots and lines). The left y-axis is for the warm spell days [days] (dots), and the right y-axis is for the inter-annual variability [days] (bars). See text (section 2.3) for details. Left panel: GSOD west, right panel: GSOD east. The corresponding slopes of the trends and their significances are given in Table $\mathbf{6}$; statistically significant trends are plotted as solid lines. 
Table 6. Seasonal Trends of Warm Spell Days [Days/Decade] Covering Different Time Periods

\begin{tabular}{|c|c|c|c|c|}
\hline & \multicolumn{2}{|c|}{ GSOD West } & \multicolumn{2}{|c|}{ GSOD East } \\
\hline & GSOD & HIRHAM & GSOD & HIRHAM \\
\hline \multicolumn{5}{|l|}{ Winter } \\
\hline \multicolumn{5}{|l|}{51 yrs (1958-2008) } \\
\hline \multicolumn{5}{|l|}{44 yrs $(1958-2001)$} \\
\hline 33 yrs (1969-2001) & 0.71 & 0.96 & 0.51 & 0.87 \\
\hline 22 yrs $(1980-2001)$ & 1.31 & 1.65 & -0.10 & -0.03 \\
\hline \multicolumn{5}{|l|}{ Spring } \\
\hline 51 yrs $(1958-2008)$ & 0.25 & & & \\
\hline 44 yrs $(1958-2001)$ & 0.19 & -0.10 & & \\
\hline 33 yrs (1969-2001) & 0.76 & 0.43 & 0.73 & 1.09 \\
\hline 22 yrs $(1980-2001)$ & 0.65 & 0.93 & 1.02 & 1.21 \\
\hline \multicolumn{5}{|l|}{ Summer } \\
\hline 51 yrs $(1958-2008)$ & 0.63 & & & \\
\hline 44 yrs $(1958-2001)$ & 0.18 & 0.10 & & \\
\hline 33 yrs $(1969-2001)$ & 0.41 & 0.51 & -0.02 & $1.73 *$ \\
\hline 22 yrs $(1980-2001)$ & 1.15 & 1.35 & 0.06 & 1.92 \\
\hline \multicolumn{5}{|l|}{ Autumn } \\
\hline 51 yrs (1958-2008) & 0.12 & & & \\
\hline 44 yrs $(1958-2001)$ & 0.22 & -0.27 & & \\
\hline 33 yrs (1969-2001) & 0.00 & -0.17 & 0.21 & 0.54 \\
\hline 22 yrs $(1980-2001)$ & 1.72 & 1.65 & -0.37 & -0.18 \\
\hline
\end{tabular}

The slopes are given for station-based (GSOD) and HIRHAM data (for details see the text of section 2). Statistically significant trends are marked with an asterisk.

In all seasons, the trends calculated in warm spell days have the same sign for ERA40 and HIRHAM for most of the modeled domain, as shown in Fig. (6). The correlation coefficients for the trend patterns are highest in winter and autumn, as for warm spell days themselves (see Table 4). Important to emphasize is that the correlation coefficients for the trends in spring and summer are higher than for the patterns of warm spell days themselves, showing that even though the total number of warm spell days is biased, the trends could be correct.

The regional analysis of warm spell days for the Russian Arctic is shown in Fig. (8). The calculated trends for both HIRHAM and the observations can be found in Table 6. Most calculated trends are positive and not statistically significant, and have the same sign and are in a similar order of magnitude for both HIRHAM and station data. An exception presents the simulated 1969-2001 summer trend for the Eastern Russian Arctic (1.7 days/decade), which is in broad disagreement with the trend calculated from observations (-0.02 days/decade). The analysis of the corresponding time series shows that from the mid 1980s on, HIRHAM generally overestimates the warm spell days in comparison with the observations, which leads to this incorrect simulated positive trend. Generally, the observed decadal changes in the inter-annual variability of the warm spells (see the bars in Fig. 8) are well captured by the model, due to the lateral and lower boundary forcing but also the regional climate feedbacks. Particularly in the Eastern Russian Arctic, the model tends to slightly overestimate the observed magnitude of the inter-annual variability, while in spring, the variability is slightly underestimated by HIRHAM.

\subsection{Growing Degree Days}

In Fig. (9), the simulated regional distribution of growing degree days for summer is shown, calculated according to the description in Table 1. The pattern is quite similar to that of ERA40 (see Fig. 8 in Matthes et al. [3]). Mainly a northsouth gradient is found, interrupted by low values over high mountain ranges. The comparison with ERA40 (see Table 7) shows that the spatial pattern is quite well reproduced by HIRHAM (pcc=0.87). The bias calculation shows that the model underestimates the growing degree days. This is partly due to the more accurate orography in HIRHAM, which leads to higher mountains compared to ERA40, associated with lower temperature and therefore lower growing degree days. Regarding the calculated trends, the agreement in the general geographical pattern is worse $(\mathrm{pcc}=0.39)$ than for growing degree days themselves. This is caused by simulated negative trends over most of the coastal areas in Russia while the ERA40 data have there zero or positive trends.

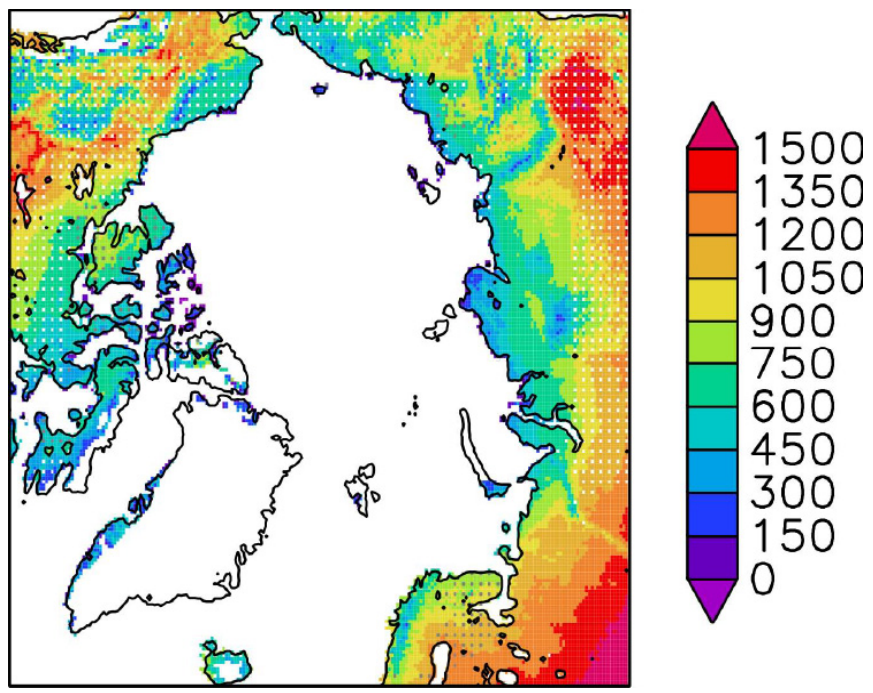

Fig. (9). Seasonal patterns of growing degree days for summer, based on the HIRHAM simulation, 1958-2001. The colors show the seasonal mean $\left[{ }^{\circ} \mathrm{C}\right]$. The dotted regions represent those areas which have the same trend sign in both ERA40 and HIRHAM. The white (grey) dotted areas indicate positive or zero (negative) trends. Bias, rmse and pcc for growing degree days and their trends are given in Table 7.

The regional analysis of the growing degree days is shown in Fig. (10). A systematic offset is found between the modeled and observed data, as HIRHAM underestimates the growing degree days but reproduces the general pattern of the observed time series very well. The inter-annual variability is well reproduced. 
Table 7. Bias $\left[{ }^{\circ} \mathrm{C}\right.$ resp. $\left.{ }^{\circ} \mathrm{C} / \mathrm{Decade}\right]$, Root Mean Square Error (rmse) $\left[{ }^{\circ} \mathrm{C}\right.$ resp. ${ }^{\circ} \mathrm{C} /$ Decade] and Pattern Correlation Coefficient (pcc) of Growing Degree Days and Growing Season Length and of their Trends Over 1958-2001, Comparison Between HIRHAM and ERA40. For Details see Section 2.3

\begin{tabular}{|c|c|c|c|c|}
\hline & $\begin{array}{c}\text { Growing } \\
\text { Degree } \\
\text { Days }\end{array}$ & $\begin{array}{c}\text { Trend in } \\
\text { Growing } \\
\text { Degree Days }\end{array}$ & $\begin{array}{c}\text { Growing } \\
\text { Season } \\
\text { Length }\end{array}$ & $\begin{array}{c}\text { Trend in } \\
\text { Growing } \\
\text { Season Length }\end{array}$ \\
\hline \hline bias & 102.7 & -14.3 & 9.89 & -1.07 \\
\hline rmse & 204.0 & 19.7 & 21.7 & 2.40 \\
\hline pcc & 0.87 & 0.39 & 0.87 & 0.39 \\
\hline
\end{tabular}

Statistically significant positive trends are found from the model as well as from the observation over the Western Russian Arctic, for both short periods and the 51-year period in the station data (see Table 8). Both the modeled and the observed trends derived for the period 1958-2001 are small (HIRHAM: $4.4{ }^{\circ} \mathrm{C} /$ decade, ERA40: $19.2{ }^{\circ} \mathrm{C} /$ decade) and not found statistically significant. In comparison to the spatial distribution of the modeled trends, this positive trend seems strange at first, as all trends calculated from HIRHAM over Western Russia are negative. This discrepancy is due to a biased time series from stations due to missing values. In the "complete" time series used for the calculation of the spatial trends, early years with high growing degree days dominate the calculated trend, which is negative. In the station time series as well as in the time series derived from interpolated model data, these years are missing. Therefore, a slight increase is calculated. For the Eastern Russian Arctic, the calculated trends are positive and found statistically significant for both the model and the station data, and the trends are in the same order of magnitude (see Table 8).

Table 8. Trends of Growing Degree Days $\left[{ }^{\circ} \mathrm{C} /\right.$ Decade] in Summer, Covering Different Time Periods

\begin{tabular}{|c|c|c|c|c|}
\hline \multirow{2}{*}{} & \multicolumn{2}{|c|}{ GSOD West } & \multicolumn{2}{c|}{ GSOD East } \\
\cline { 2 - 5 } & GSOD & HIRHAM & GSOD & HIRHAM \\
\hline \hline 51 yrs (1958-2008) & $37.4^{*}$ & & & \\
\hline 44 yrs (1958-2001) & 19.2 & 4.4 & & \\
\hline 33 yrs (1969-2001) & $61.9^{*}$ & $53.8^{*}$ & $84.7^{*}$ & $91.02^{*}$ \\
\hline 22 yrs (1980-2001) & $105.0^{*}$ & $102.0^{*}$ & $97.19^{*}$ & $110.7^{*}$ \\
\hline
\end{tabular}

The numbers are given for station-based (GSOD) and HIRHAM data (for details see the text of section 2). Statistically significant trends are marked with an asterisk.



\subsection{Growing Season Length}

The growing season length over the Arctic domain as calculated from HIRHAM is shown in Fig. (11). The spatial distribution shows a north-south gradient over the whole Arctic as well as an east-west gradient over Eurasia as known from ERA40 data (Fig. 10 in Matthes et al., [3]) and satellite data (e.g., Smith et al., McDonald et al. $[15,16])$. As in the growing degree days, high mountains are clearly depicted by low values. The quantification of the comparison of HIRHAM with ERA40 data is given in Table 7 . The high pattern correlation ( $\mathrm{pcc}=0.87$ ) indicates a good reproduction of the geographical pattern. The analysis of the bias patterns shows that the growing season length calculated from HIRHAM is shorter than those from ERA40 data over mountain ranges, due to the fact that HIRHAM has a higher resolution and therefore a better represented orography. Also, some areas (Taimyr Peninsula and the islands north of the Canadian coast) with positive biases are found. This can be associated with the negative bias found in frost days in spring over the same areas, indicating that HIRHAM warms too early in spring, which leads to less frost days and a longer growing season length.

The trend analysis shows positive trends over most of the modeled area, with exceptions over the coastal Eastern Russian Arctic. The pattern correlation calculated for the trends is much smaller ( $\mathrm{pcc}=0.39$ ) than for the growing season length itself (see Table 7). This discrepancy is mainly caused by negative trends over the Taimyr Peninsula and the Eastern Russian Arctic as compared to positive trends derived from ERA40 data. A further comparison with satellite-derived growing season length data as given in Smith et al. [15] shows that HIRHAM actually better represents those observations than ERA40.

\section{SUMMARY AND CONCLUSIONS}

In this study, several climate indices based on daily temperature data as calculated by the RCM HIRHAM are analyzed concerning the ability of the model to reproduce the observed patterns. Data from the ERA40 reanalysis as well as station data have been examined to compare the spatial distribution of the indices and their regional-scale details. Temperature-related indices expressing temperature extremes, i.e. frost days, warm and cold spell days, growing degree days and growing season length are investigated.

The spatial analysis of frost days shows that HIRHAM well captures the patterns from observations, and the regional analysis demonstrates the model's ability to reproduce the remarkable year-to-year variability found in the station data.



Fig. (10). Year-to-year variability and trends of growing degree days for summer, 1958-2008, based on station data (green dots and lines) and HIRHAM (black dots and lines). The left y-axis is for the growing degree days [days] (dots), and the right y-axis is for the inter-annual variability [days] (bars). See text (section 2.3) for details. Left panel: GSOD west, right panel: GSOD east. The corresponding slopes of the trends and their significances are given in Table $\mathbf{8}$; statistically significant trends are plotted as solid lines. 

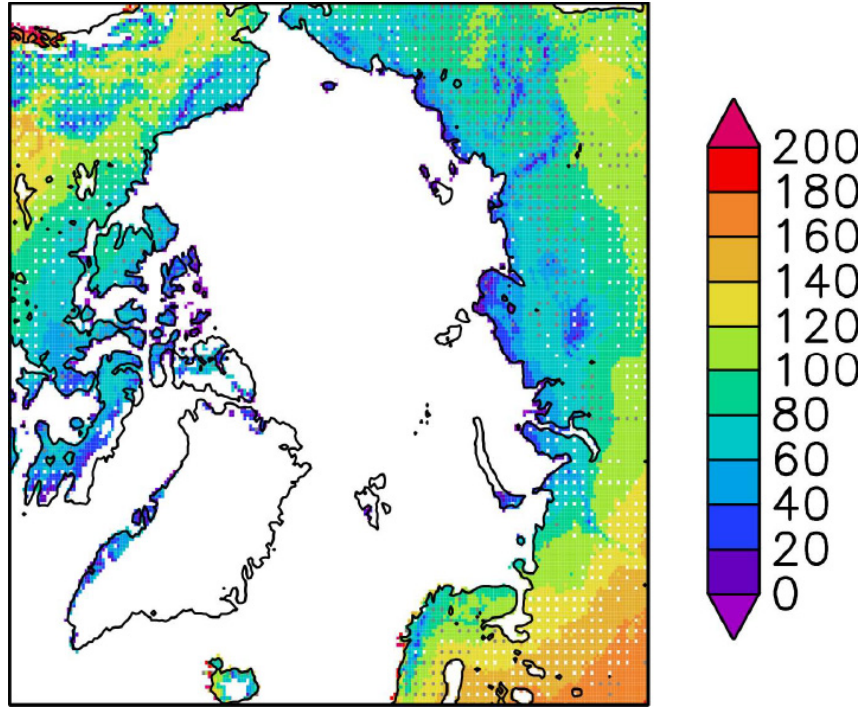

Fig. (11). Seasonal patterns of growing season length, based on the HIRHAM simulation, 1958-2001. The colors show the annual mean $\left[{ }^{\circ} \mathrm{C}\right]$. The dotted regions represent those areas which have the same trend sign in both ERA40 and HIRHAM. The white (grey) dotted areas indicate positive ore zero (negative) trends. Bias, rmse and pcc for growing season length and its trends are given in Table $\mathbf{5}$.

The spatial distribution of cold spell days is strongly associated with predominant atmospheric circulation patterns in the corresponding years. These are well reproduced by HIRHAM, and therefore the general patterns in cold spell days are captured by the model except for summer over the Arctic Ocean

Concerning warm spell days, the performance of the model strongly depends on the season. While the modeled and observed patterns agree for both autumn and winter, distinct differences occur for spring and summer. As the occurring problems are concentrated on the Arctic Ocean, the regional analysis for Eastern and Western Arctic Russia shows good agreement between station data and HIRHAM.

Growing degree days are systematically underestimated by HIRHAM. However, the calculated spatial patterns as well as the trends and decadal-scale variability in the time series are well reproduced. The model shows the same positive trends in the regional analysis as the station data. The growing season length is underestimated over large parts of the Arctic by HIRHAM, though overestimations are found over the Taimyr Peninsula and parts of the Canadian Archipelago. The trends and their patterns are well reproduced by HIRHAM.

In general, we find that the analyzed climate indices as calculated from output of the HIRHAM model agree well with the calculations based on observations. The spatial and temporal patterns as well as the variability and trends are well reproduced for the majority of the analyzed indices and seasons. The analysis presented in this study clearly demonstrates the ability of the model to capture climate extremes as defined by the used indices, and therefore enhances its use for climate simulations for future periods.

\section{ACKNOWLEDGEMENTS}

This research has been funded by the European Union project CARBO-North. We are grateful to I. Hebestadt for programing support. We thank the reviewers for their constructive comments.

\section{REFERENCES}

[1] Rinke A, Dethloff K. Simulated circum-Arctic climate changes by the end of the 21st century. Glob Planet Change 2008; 62: 173-86

[2] Alexander LV, Zhang X, Peterson TC, et al. Global observed changes in daily climate extremes of temperature and precipitation. J Geophys Res 2006; 111: D05109

[3] Matthes H, Rinke A, Dethloff K. Variability of observed temperature-derived climate indices in the Arctic. Glob Planet Change 2009; 69: 214-24.

[4] Kiktev D, Sexton DMH, Alexander L, Folland CK. Comparison of modelled and observed trends in indices of daily climate extremes. J Clim 2203; 16: 3560-71.

[5] Uppala SM, Kålberg PW, Simmons AJ, et al. The ERA-40 reanalysis. Quart J Roy Meteor Soc 2005; 130: 2961-3012.

[6] Christensen JH, Christensen OB, et al. The HIRHAM4 regional atmospheric climate model, DMI Sci. Rep. 96-4, Dan. Meteorol Inst, Copenhagen, Denmark 1996.

[7] Dethloff K, Rinke A, Lehmann R, Christensen JH, Botzet M, Machenhauer B. Regional climate model of the Arctic atmosphere. J Geophys Res 1996; 101: 23401-23422.

[8] Gustafsson N. HIRLAM2 final report, HIRLAM Tech. Rep. 9; Swed. Meteorol. And Hydrol. Inst., Norrköping, Sweden 1993.

[9] Roeckner E, Arpe K, Bengtsson L, et al. The atmospheric general circulation model ECHAM-4: Model description and simulation of present-day climate; MPI Rep. 218, Max Planck Inst. for Meteorol, Hamburg, Germany 1996.

[10] Bonan GB. A land surface model (LSM version 1.0) for ecological, hydrological, and atmospheric studies: technical description and user's guide; NCAR Tech. Note TN-417+STR, National Center for Atmospheric Research, Boulder, Colorado 1996.

[11] Saha SK, Rinke A, Dethloff K, Kuhry P. The influence of a complex land surface scheme on Arctic climate simulations. Journal of Geophysical Research - Atmospheres 2006; 111: D22104, doi:10.1029/2006JD007188.

[12] Peterson TC, Folland C, Gruza G, Hogg W, Mokssit A, Plummer N. Report on the Activities of the Working Group on Climate Change Detection and Related Rapporteurs 1998-2001; WMO, Rep. WCDMP-47, WMO-TD 1071, Geneve, Switzerland 2001.

[13] Rinke A, Dethloff K, Spekat A, Enke W, Christensen JH. High resolution climate simulations over the Arctic. Polar Res 1999; 18: $1-9$.

[14] Inoue J, Liu J, Pinto JO, Curry J. Intercomparison of Arctic regional climate models: Modelling clouds and radiation for SHEBA in May 1998. J Climate 2006; 19 (17): 4167-78.

[15] Smith NV, Saatchi SS, Randerson JT. Trends in high northern latitude soil freeze and thaw cycles from 1988 to 2002. J Geophys Res 2004; 109: D12101.

[16] McDonald KC, Kimball JS, Njoku E, Zimmermann R, Zhao M. Variability in Springtime thaw in the terrestrial high latitudes: Monitoring a major control on the biospheric assimilation of atmospheric $\mathrm{CO}_{2}$ with spaceborne microwave remote sensing. Earth Interactions 2004; 8(20): 1-23. 